\title{
Ursula Haskins Gonthier et Alain Sandrier (dir.), Multilinguisme et multiculturalité dans l'Europe des Lumières. Multilingualism and Multiculturalism in Enlightenment Europe
}

Raymonde Monnier

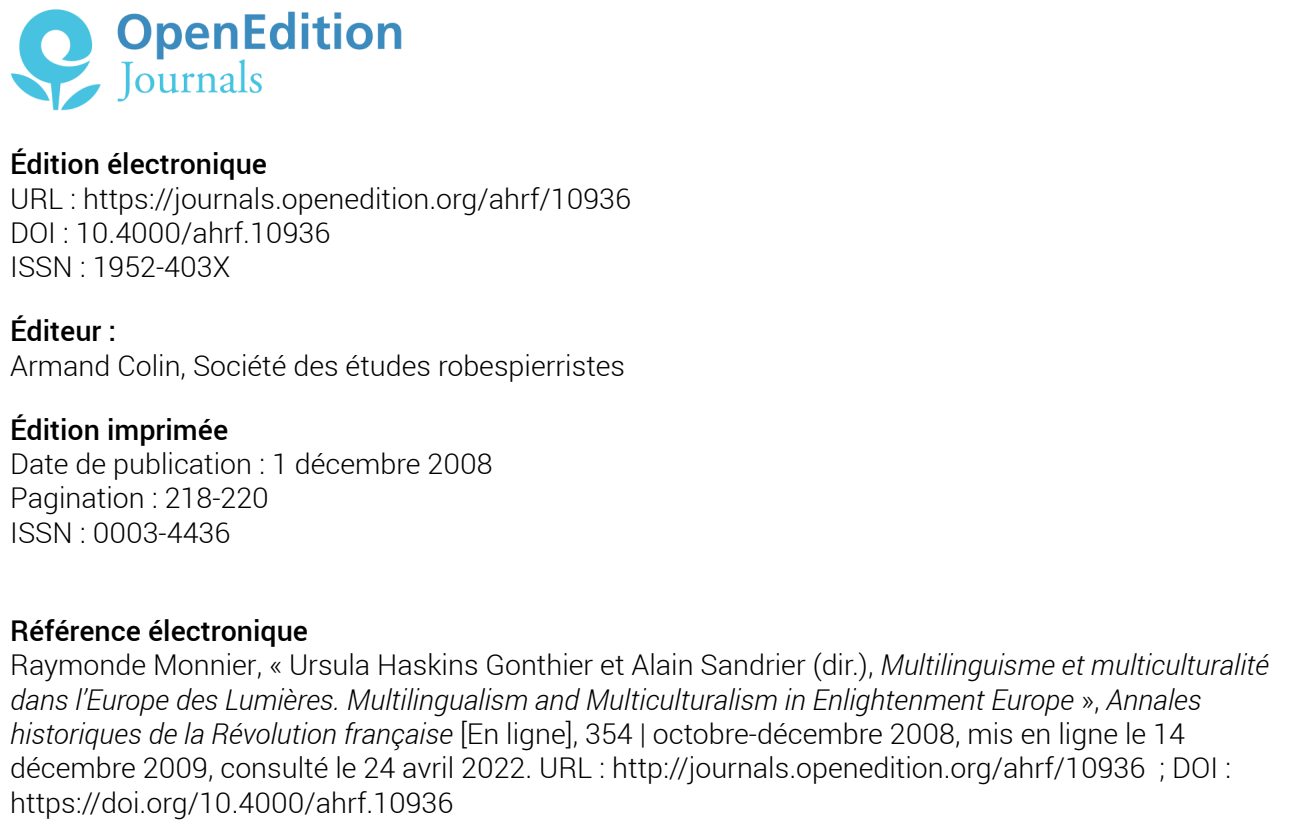

Ce document a été généré automatiquement le 24 avril 2022

Tous droits réservés 


\title{
Ursula Haskins Gonthier et Alain Sandrier (dir.), Multilinguisme et multiculturalité dans l'Europe des Lumières. Multilingualism and Multiculturalism in Enlightenment Europe
}

\author{
Raymonde Monnier
}

\section{RÉFÉRENCE}

Ursula Haskins Gonthier et Alain Sandrier (dir.), Multilinguisme et multiculturalité dans l'Europe des Lumières. Multilingualism and Multiculturalism in Enlightenment Europe, Paris, Honoré Champion, 2007, 285 p., ISBN 978-2-7453-1565-6, $55 €$

1 Ce livre réunit une douzaine de contributions, présentées en français et en anglais au séminaire organisé au château de Beuggen, près de Bâle, par les sociétés suisse et allemande d'Études du dix-huitième siècle, dont le thème était proposé par HansJürgen Lüsebrink et Andres Kristol. Le concept de multiculturalité utilisé par les sociologues et les politologues est un concept contemporain relativement récent, venu du contexte social nord-américain; en quoi peut-il être justifié de l'utiliser pour la recherche sur le XVIII ${ }^{e}$ siècle ? C'est le problème que présente Lüsebrink en première partie: le concept peut s'appliquer aux sociétés selon différents modes, celui de la diversité des cultures, ceux de l'assimilation ou de l'intégration des minorités, ou celui de l'apartheid dans certaines sociétés coloniales. Le terme est lié à ceux d'interculturalité et au concept plus large de transculturalité, qui désignent des formes de contact et d'interaction créative entre différents groupes, qu'il s'agisse de processus 
de métissages ou de transferts culturels, selon une théorie présente notamment dans les travaux allemands depuis les années 1980, et qu'illustrent plusieurs articles du présent volume. Les phénomènes analysés montrent une grande différence de perspective avec le multiculturalisme des sociétés contemporaines. Le concept de nation n'ayant pas au XVIII ${ }^{\mathrm{e}}$ siècle le poids qu'il prend par la suite, les critères culturels sociaux ou religieux semblent les plus pertinents: d'un côté, le clivage entre culture protestante et catholique, ou entre culture chrétienne et juive, qui ont modelé les systèmes culturels et symboliques, et de l'autre les pratiques socioculturelles qui dominent l'univers des couches populaires ou celui des élites et des cours princières. Le concept de plurilinguisme dans l'Europe des Lumières fait l'objet d'une présentation neuve d'Andres Kristol, à travers une approche sociolinguistique qui s'appuie sur une lecture et une observation fine de documents historiques connus - dont l'enquête sur les «patois » de Grégoire en 1794 - sur l'espace "francophone » (France et Suisse romande). L'étude linguistique met en relief le fait que si en France même tout le monde ne parlait pas la forme de langue appelée française à une époque où « l'Europe parlait français ", dans toutes les provinces de France la communication s'établissait sur un double bilinguisme passif où chacun des locuteurs connaissait la langue de l'autre sans l'utiliser : une situation linguistique complexe où cohabitaient le français et les formes littéraires et orales de la langue vernaculaire. La francisation, jusque dans la première moitié $\mathrm{du} \mathrm{XIX}^{\mathrm{e}}$ siècle, n'a pas encore fait disparaître chez les différents auteurs la deuxième langue dont l'usage reste surtout oral. L'auteur peut ainsi conclure qu' » être bilingue, voire multilingue - et avoir appris le français à l'école - était le lot commun de l'énorme majorité des Européens "francophones" de l'époque, en France comme à l'étranger»(p. 47). La diversité au niveau linguistique et culturel est présentée en deux grandes séquences, traitant respectivement de l'évolution au sein des territoires ( $2^{\mathrm{e}}$ partie) et des principaux vecteurs et médiateurs des mutations sociales ( $3^{\mathrm{e}}$ et $4^{\mathrm{e}}$ parties), avec une attention particulière à l'histoire du livre, à l'imprimé et aux problèmes de la traduction. Plusieurs chercheurs peuvent ainsi présenter leurs travaux personnels ou des projets collectifs.

2 Du côté de la recherche historique, Johannes Frimmel présente le projet autrichien sur le marché du livre dans la monarchie des Habsbourg, espace multiethnique exemplaire marqué par la multiculturalité dont il s'agit de comprendre l'évolution complexe face aux tendances contradictoires de l'unification et de la résistance des identités. Le métissage culturel des minorités et la diversité linguistique, qu'ils soient le fait de la politique religieuse des États ou du jeu des frontières, comme en Pologne

(Ulrich Müller), posent évidemment des problèmes spécifiques. Et comment saisir le rapport entre dynamique culturelle cosmopolite des élites et identité politique nationale des individus? C'est ce que tente Carlotta Wolf pour la Suède, à travers l'étude de quelques personnages haut placés, ayant un vaste réseau de relations et de correspondances à l'étranger dans les cercles intellectuels et mondains. Le français, réputé universel, subit aussi des effets d'acculturation. La situation linguistique de diglosie décrite par Andres Kristol peut être observée à Berlin dans la deuxième moitié du XVIIIe siècle par Manuela Böhm à partir d'exemples précis. Dans la «colonie française " des réfugiés huguenots, un lent processus d'assimilation aboutit à une situation multilinguistique complexe où «le français a la fonction d'une langue de culte et de culture, et l'allemand, voire le Berlinisch, celle de langue courante » (p. 63). En une centaine d'années, le français de lingua franca et lingua sacra, « s'est réduite au culte et à 
la distinction sociale ». D'autre part, quels furent les principaux vecteurs de la diffusion et de l'apprentissage du français dans la haute société russe? L'article de Vladislav Rzeutskij reconstitue les grandes étapes de la pénétration de la langue et de la culture française à différents niveaux de la noblesse, dans une étude très documentée sur les pratiques sociales, l'enseignement dans les pensionnats et les grandes maisons, les réseaux francophones, le théâtre, grâce aux différents médiateurs - précepteurs, journalistes et artistes - et à certains grands promoteurs des Lumières comme Ivan Ivanovic Suvalov. Les traductions jouent évidemment un rôle non négligeable, mais elles répondent à des objectifs divers. En Allemagne, l'analyse de deux catalogues commentés de riches bibliothèques privées (à la cour de Weimar et en Bavière) montre que la traduction de romans français en italien par exemple, pouvait servir à l'apprentissage de la langue (Nathalie Ferrand). Quant au catalogue raisonné, il pouvait selon le cas participer de la sociabilité de cour ou du laboratoire de l'érudit. Dans les livrets d'opéra, étudiés par Gunilla Eschenbach à Hambourg, le mélange des langues a une fonction de critique sociale : l'usage satirique de l'italien et du français dénote une attitude antiaristocratique que partagent les publics, contre la galanterie et la politesse, au profit des valeurs des classes urbaines. On peut se demander pourquoi, alors que la Hollande est au siècle des Lumières "la librairie du monde ", on constate dans les traductions du français une quasi absence de livres philosophiques, et une tendance conservatrice assez nette dans le choix des textes théologiques et les nombreuses pièces traduites pour le théâtre d'Amsterdam? Sans doute, comme l'avance Edwin van Meerkerk, le marché des traductions n'était-il pas concerné par les textes philosophiques que le public hollandais pouvait se procurer sur place et qu'il lisait en français. On sait la renommée de la presse périodique anglaise dès le début du siècle. La traduction relativement tardive (1783) en hongrois d'articles choisis du Spectator d'Addison et Steele par un pasteur réformé, dont Péter Balazs prépare l'édition critique, répond cependant moins au désir d'introduire le lecteur hongrois à une pratique dialogique de journalisme qu'au souci de donner à lire sous une forme agréable un manuel édifiant de morale laïque. Le Spectator et la presse anglaise avaientils déjà inspiré Montesquieu? Ursula Haskins Gonthier montre en quoi le texte des Lettres persanes, dont la rhétorique est imitée outre-Manche autour de 1730 dans la presse politique participe de la communication interculturelle. Enfin, deux figures emblématiques de ce métissage culturel et linguistique sont évoquées dans la dernière partie du livre. Celle du prince Démètre Cantemir (Cristina Bîrsan), qui sut mettre à profit les aléas de sa vie politique, entre son pays natal, la Moldavie, Istanbul et la cour de Pierre le Grand, pour construire une carrière de savant particulièrement originale : à cheval entre les cultures musulmane et chrétienne, entre le monde grec, l'Orient et l'Occident, il innove en divers domaines, laissant une œuvre écrite en plusieurs langues, dont une Description de la Moldavie et une Histoire de l'Empire ottoman dont les traductions furent durablement appréciées en Europe. La contribution d'Alain Sandrier, consacrée au baron d'Holbach, analyse le double jeu du philosophe qui a une parfaite maîtrise des langues qu'il traduit en français. S'il insiste dans ses traductions scientifiques très officielles de l'allemand sur son souci d'être utile et de servir l'État, pour les œuvres traduites de l'anglais, il en va tout autrement. L'exemple de L'Esprit du clergé, traduction de The Independent Whig de Gordon et Trenchard est révélateur de la manière dont il réoriente les arguments pour déplacer la thèse anti-athée des auteurs vers un horizon athée dédramatisé. On voit toute la richesse de ce séminaire consacré à la diversité culturelle et linguistique des Lumières, qui était lui-même traversé par la 
multiculturalité en rassemblant des chercheurs de plusieurs disciplines venant de dix pays d'Europe. 